BMC

Pediatrics

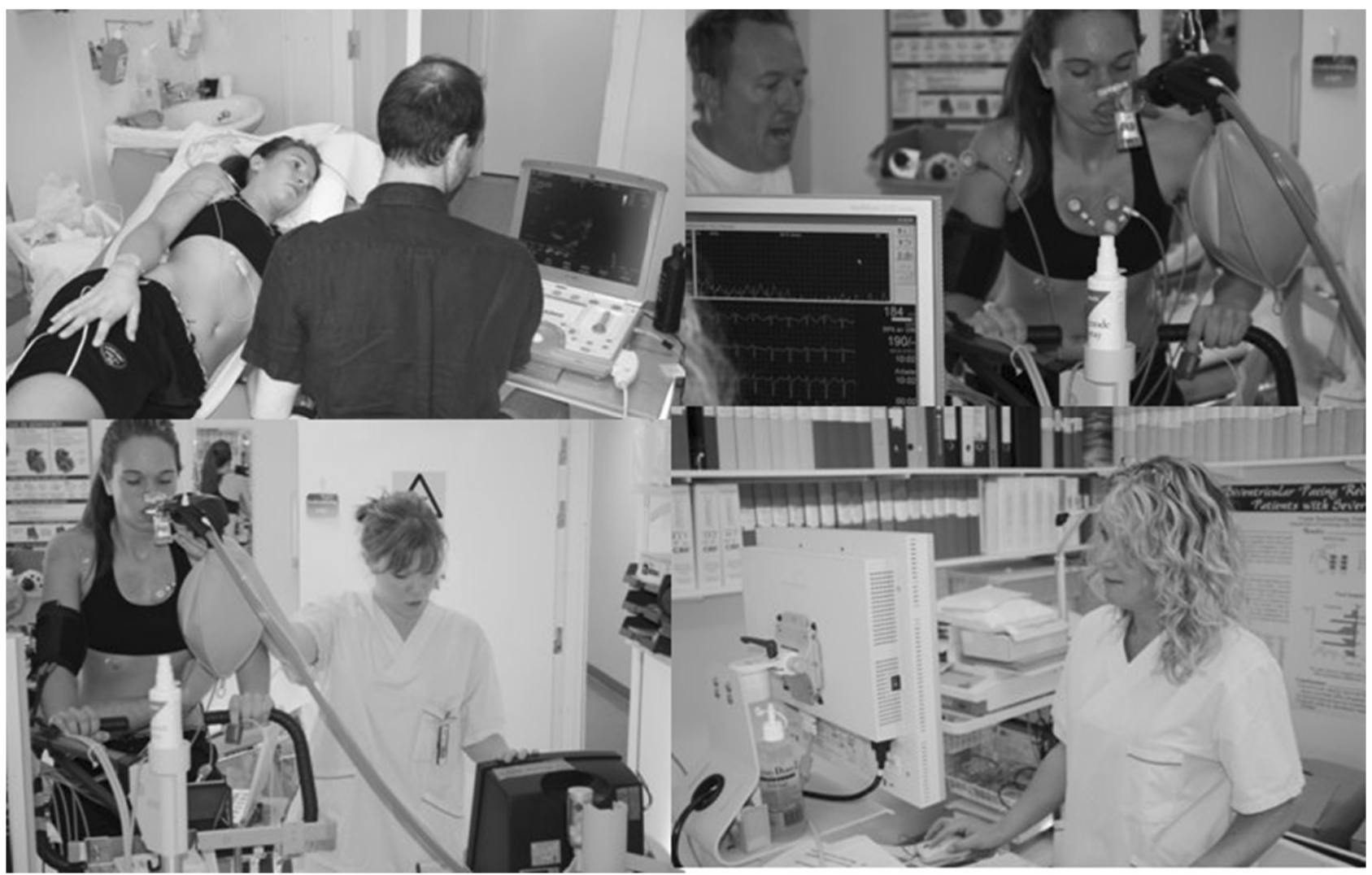

Sex differences in response to maximal exercise stress test in trained adolescents

Fomin et al. 


\title{
Sex differences in response to maximal exercise stress test in trained adolescents
}

\author{
Åsa Fomin ${ }^{\dagger}$, Mattias Ahlstrand ${ }^{\dagger}$, Helena Gyllenhammar Schill, Lars H Lund, Marcus Ståhlberg, \\ Aristomenis Manouras ${ }^{\dagger}$ and Anders Gabrielsen ${ }^{*}$
}

\begin{abstract}
Background: Sex comparisons between girls and boys in response to exercise in trained adolescents are missing and we investigated similarities and differences as a basis for clinical interpretation and guidance.

Methods: A total of 24 adolescent females and 27 adolescent males aged 13-19 years underwent a maximal bicycle exercise stress test with measurement of cardiovascular variables, cardiac output, lung volumes, metabolic factors/lactate concentrations and breath-by-breath monitoring of ventilation, and determination of peak $\mathrm{VO}_{2}$.

Results: Maximum heart rate was similar in females (191 $\pm 9 \mathrm{bpm})$ and males (194 $\pm 7 \mathrm{bpm})$, cardiac index at maximum exercise was lower in females $\left(7.0 \pm 1.0 \mathrm{l} / \mathrm{min} / \mathrm{m}^{2}\right)$ than in males $\left(8.3 \pm 1.4 \mathrm{l} / \mathrm{min} / \mathrm{m}^{2}, \mathrm{P}<0.05\right)$. Metabolic responses and $\mathrm{RQ}$ at maximum exercise were similar (females: $1.04 \pm 0.06$ vs. males: $1.05 \pm 0.05$ ). Peak $\mathrm{VO}_{2}$ was lower in females $(2.37 \pm 0.34 \mathrm{l} / \mathrm{min})$ than in males $(3.38 \pm 0.49 \mathrm{l} / \mathrm{min}, \mathrm{P}<0.05)$. When peak $\mathrm{VO}_{2}$ was normalized to leg muscle mass sex differences disappeared (females: $161 \pm 21 \mathrm{ml} / \mathrm{min} / \mathrm{kg}$ vs. males: $170 \pm 23 \mathrm{ml} / \mathrm{min} / \mathrm{kg}$ ). The increase in cardiac index during exercise is the key factor responsible for the greater peak $\mathrm{VO}_{2}$ in adolescent boys compared to girls.
\end{abstract}

Conclusions: Differences in peak $\mathrm{VO}_{2}$ in adolescent boys and girls disappear when peak $\mathrm{VO}_{2}$ is normalized to estimated leg muscle mass and therefore provide a tool to conduct individual and intersex comparisons of fitness when evaluating adolescent athletes in aerobic sports.

Keywords: Adolescent, Sex, Body composition, Exercise stress test, ECG, Blood pressure, Peak $\mathrm{VO}_{2}$, Ventilation, Lactate

\section{Background}

Physical activity and training is important for initiating and sustaining cardiovascular health. As such, encouragement from childhood and the possibility to participate in sports activity is a major health issue which must be sustained. Reaching adolescence, however, increasing expectations and competitive demands have gradually emerged as an important aspect of recreational sports in the young. During the past decades there has been a gradual increase in the number of teenagers participating in competitive sports and the number of female athletes has increased in aerobic team sports $[1,2]$ - in Sweden in particular in soccer, floor-ball and ice-hockey

\footnotetext{
* Correspondence: Anders.Gabrielsen@ki.se

${ }^{\dagger}$ Equal contributors

Department of Cardiology, Karolinska Institutet, Karolinska University Hospital, N1:05, SE-17176, Stockholm, Sweden
}

\section{() Biomed Central}

[3]. Correct and adequate planning of physical and exercise training is instrumental in providing the young athlete with a sustained career, increase endurance and enhance musculo-skeletal stability and avoiding injuries, fatigue or physical scarring.

Adolescence is the age interval at which the young sport competitor starts building local and national team careers, prompting coaches and physical trainers to interpret test results and understand and take into account possible sex-specific characteristics. At the moment, however, detailed knowledge about sex-related differences in adolescent exercise physiology is limited. Maximal oxygen uptake has been extensively investigated in children [4-7] and adults [8], but clinical context sex comparisons in the adolescent age-group 13 to 19 years of age in trained subjects are missing. 
This impedes our interpretation of the cardiovascular and respiratory responses to exercise in adolescent girls compared to boys and limits our guidance in exercise programs in adolescents in competitive sports. It is essential to acknowledge possible differences between male and female participants which, if present, must be taken into account when planning and performing physical exercise programs for the adolescent athlete. Differences between male and female participants may prompt the development of sex-specific programs, and be valuable when evaluating training levels and differentiating pathology from normality in youth sports.

Because clinical performance reference data are missing we performed a detailed comparative characterization of cardiovascular, respiratory and metabolic responses to maximum exercise in aerobically trained adolescent boys and girls, with the aim being to identify similarities and differences as a basis for clinical interpretation and guidance.

\section{Results}

\section{Subjects and physical characteristics}

One female participant was diagnosed with a WolfParkinson-White type pre-excitation but was included in the study as she was completely asymptomatic. She was referred for cardiac electrophysiological evaluation. Her other exams and test results, beside the ECG, were completely normal. All other subjects had a normal medical history, a normal physical exam, and normal pre-study echo-cardiographic exam.

All exercise trials were terminated due to general fatigue with maximum leg fatigue, whereas no trial was stopped prematurely because of dyspnea, chest pain or cardiac arrhythmias.

Age was similar in males and females, the males being taller and heavier but with similar body mass index compared to female athletes (Table 1). In addition, expected differences in segmental body composition, hemoglobin and creatinine were observed (Table 1). Female subjects participated in formal training and/or exercise a little less than did male subjects (Table 1). When comparing baseline ECG characteristics only QTc interval differed between female and male subjects (Table 1). No differences in plasma concentrations of $\mathrm{Na}^{+}$and $\mathrm{K}^{+}$, plateletor leukocyte counts were observed (data not shown).

\section{Resting cardiopulmonary and metabolic characteristics}

Female subjects exhibited a lower systolic blood pressure $(124 \pm 11 \mathrm{mmHg}$; mean $\pm \mathrm{SD})$ and higher resting heart rate $(77 \pm 8 \mathrm{bpm})$ compared to male participants $(137 \pm 13 \mathrm{mmHg}$ and $71 \pm 11 \mathrm{bpm}$, respectively; $\mathrm{P}<0.05)$, whereas diastolic blood pressure (females: $74 \pm 8 \mathrm{mmHg}$ vs. males: $72 \pm 11 \mathrm{mmHg}$ ) and resting cardiac index (females: $3.8 \pm 0.8 \mathrm{l} / \mathrm{min} / \mathrm{m}^{2}$ vs. males: $4.1 \pm 1.0 \mathrm{l} / \mathrm{min} / \mathrm{m}^{2}$ ) did not differ between sexes (Figure 1). Ventilated lung volumes at rest were lower in females than in males $(\mathrm{P}<0.05$, Table 2). There were no differences in metabolic variables; blood lactate concentration, blood $\mathrm{pH}$, blood base excess, and blood $\mathrm{HCO}_{3}^{-}$at rest (Table 2). At 60 watt (initial step) exercise absolute $\mathrm{VCO}_{2}$ were slightly lower in females $(0.55 \pm 0.13 \mathrm{l} / \mathrm{min})$ than in males $(0.65 \pm 0.11 \mathrm{l} / \mathrm{min}$, $\mathrm{p}<0.05$ ), whereas $\mathrm{VO}_{2}$ did not differ (females: $0.79 \pm 0.12 \mathrm{l}$ / min vs. males: $0.85 \pm 0.15 \mathrm{l} / \mathrm{min}$ ) leading to a minor difference in RQ (females: $0.71 \pm 0.12$ vs. males: $0.77 \pm 0.08$, $\mathrm{P}<0.05)$. Ventilation volumes at this initial step of exercise were similar comparing females and males (Table 2).

\section{Cardiopulmonary and metabolic responses to exercise}

Maximum systolic blood pressure during exercise was lower in female $(171 \pm 20 \mathrm{mmHg})$ than in male subjects $(185 \pm 17 \mathrm{mmHg}, \mathrm{p}<0.05)$, whereas maximum heart rate was similar (females: $191 \pm 9 \mathrm{bpm}$ vs. males $194 \pm 7 \mathrm{bpm}$, Figure 1). Cardiac index at maximum exercise was lower in females $\left(7.0 \pm 1.0 \mathrm{l} / \mathrm{min} / \mathrm{m}^{2}\right)$ than in males $(8.3 \pm 1.4 \mathrm{l} / \mathrm{min} /$ $\mathrm{m}^{2}, \mathrm{P}<0.05$, Figure 1$)$. Ventilation and ventilated lung volume at maximum exercise were significantly lower in females than in males $(\mathrm{P}<0.05$, Table 2$)$, whereas metabolic responses to maximum exercise were very similar with only a minor incremental increase in blood lactate levels in males compared to females and without differences in blood $\mathrm{pH}$, blood base excess, or blood $\mathrm{HCO}_{3}^{-}$(Table 2). Peak $\mathrm{VCO}_{2}$ were lower in females $(2.45 \pm 0.36 \mathrm{l} / \mathrm{min})$ than in males $(3.50 \pm 0.51 \mathrm{l} / \mathrm{min})$ but was matched to peak $\mathrm{VO}_{2}$ in a similar manner in both sexes as RQ at maximum exercise was similar (females: $1.04 \pm 0.06$ vs. males: $1.05 \pm 0.05$ ). Absolute peak $\mathrm{VO}_{2}$, peak $\mathrm{VO}_{2}$ normalized to total body mass, and peak $\mathrm{VO}_{2}$ normalized to lean body mass were lower in females $(2.37 \pm 0.34 \mathrm{l} / \mathrm{min} ; 39.1 \pm 5.1 \mathrm{ml} / \mathrm{min} / \mathrm{kg}$; $51.2 \pm 6.8 \mathrm{ml} / \mathrm{min} / \mathrm{kg}$, respectively) compared to males $(3.38 \pm 0.49 \mathrm{l} / \mathrm{min} ; 48.7 \pm 5.5 \mathrm{ml} / \mathrm{min} / \mathrm{kg} ; 56.0 \pm 7.6 \mathrm{ml} / \mathrm{min} /$ $\mathrm{kg}$, respectively, $\mathrm{P}<0.05$; Figure 2), but when peak $\mathrm{VO}_{2}$ was normalized to leg muscle mass sex differences disappeared (females: $161 \pm 21 \mathrm{ml} / \mathrm{min} / \mathrm{kg}$ vs. males: $170 \pm 23 \mathrm{ml} / \mathrm{min} / \mathrm{kg}$; Figure 2). Normalization of peak $\mathrm{VO}_{2}$ to estimated leg muscle mass, when compared to normalization to total body mass/lean body mass had an impact on the classification rank of training-level in girls. In our group of girls, 25\% $(\mathrm{N}=6)$ were reclassified and shifted from the half of subjects with peak $\mathrm{VO}_{2}$ below the median to the group above the median when normalization to total body mass/lean body mass was compared to peak $\mathrm{VO}_{2}$ normalization to estimated leg muscle mass. This impact of normalization on classification rank of training-level was less apparent in boys (2 subjects reclassified) - mainly because their estimated fat mass in legs exhibits very low levels with low variation.

\section{Discussion}

In this investigation we demonstrate expected sex differences in the response to a maximal bicycle stress exercise 
Table 1 Baseline characteristics of the study subjects

\begin{tabular}{|c|c|c|c|}
\hline & Females $(n=24)$ & Males $(n=27)$ & P-value \\
\hline Age (years) & $16.5 \pm 1.8$ & $17.0 \pm 1.3$ & 0.26 \\
\hline Height $(\mathrm{cm})$ & $168 \pm 5$ & $179 \pm 6$ & $P<0.001$ \\
\hline Weight (kg) & $61.3 \pm 9.2$ & $69.7 \pm 9.1$ & $P=0.002$ \\
\hline BMI $\left(\mathrm{kg} / \mathrm{m}^{2}\right)$ & $21.6 \pm 2.8$ & $21.7 \pm 2.7$ & $P=0.84$ \\
\hline Training pr week (hours) & $7.4 \pm 1.6$ & $8.8 \pm 1.3$ & $P=0.002$ \\
\hline Total body fat (kg/\%) & $15.1 \pm 5.3 / 23.1 \pm 6.5$ & $8.9 \pm 4.2 / 12.7 \pm 5.1$ & $\mathrm{P}<0.001$ \\
\hline Total body fat free mass $(\mathrm{kg})$ & $46.6 \pm 5.3$ & $60.7 \pm 7.7$ & $\mathrm{P}<0.001$ \\
\hline Total leg muscle mass $(\mathrm{kg})$ & $15.0 \pm 1.9$ & $20.0 \pm 2.7$ & $P<0.001$ \\
\hline Hemoglobin $(g / l)$ & $132 \pm 6$ & $147 \pm 8$ & $\mathrm{P}<0.001$ \\
\hline Creatinine $(\mu \mathrm{mol} / \mathrm{l})$ & $65 \pm 10$ & $78 \pm 9$ & $P<0.001$ \\
\hline \multicolumn{4}{|l|}{ Resting ECG parameters } \\
\hline PR interval (msec) & $149 \pm 21(149 \pm 21 ; N=23)$ & $144 \pm 14$ & $P=0.39$ \\
\hline QRS duration (msec) & $95 \pm 20(92 \pm 7.6 ; N=23)$ & $99 \pm 9.9$ & $P=0.43$ \\
\hline QTc (msec) & $440 \pm 36(435 \pm 25 ; N=23)$ & $417 \pm 20$ & $P=0.007$ \\
\hline$P$ axis $\left(^{\circ}\right)$ & $52 \pm 26(52 \pm 26 ; N=23)$ & $50 \pm 28$ & $P=0.79$ \\
\hline QRS axis $\left(^{\circ}\right)$ & $65 \pm 38(70 \pm 29 ; N=23)$ & $80 \pm 24$ & $P=0.10$ \\
\hline T axis $\left(^{\circ}\right)$ & $59 \pm 47(50 \pm 17 ; N=23)$ & $54 \pm 17$ & $P=0.57$ \\
\hline
\end{tabular}

Values are expressed as mean \pm SD. Rows in bold denotes a statistical significant difference $(P<0.05)$ between females and males. $P$-values represent values after correction for multiple testing. In the section reporting ECG parameters female data is presented with $(\mathrm{N}=24)$ and without ( $\mathrm{N}=23$; parentheses) inclusion of the subject with WPW-type pre-excitation.

test in trained adolescents [8] and that the cardiovascular, respiratory and metabolic differences are essentially similar to those observed in adults [8-10]. We also demonstrate that maximum heart rate, systemic lactate levels, and RQ are similar in adolescent boys and girls, which indicates that maximum performance is associated with the same metabolic adaptation irrespective of sex. However, we observe that the normally observed difference in peak $\mathrm{VO}_{2}$ per kilogram body mass comparing boys and girls disappears when peak $\mathrm{VO}_{2}$ is normalized to leg muscle mass only. This finding suggests that, when applied to aerobically trained subjects, there is a close relationship between leg muscle mass and peak $\mathrm{VO}_{2}$ and that peak $\mathrm{VO}_{2}$ normalized to leg muscle mass serves as a guiding measure when evaluating the individual level of aerobic performance and comparing the degree of fitness between boys and girls in aerobic sports.

The cardiopulmonary and metabolic response to a maximal bout of exercise has been well studied in adults and differences between sexes have been previously described $[8,10]$. However, when we were to start an evaluation program of the training levels and physical performances of adolescent female floor-ball players, it was unclear which peak $\mathrm{VO}_{2}$ levels, and metabolic 
Table 2 Response to exercise of selected ventilatory and metabolic variables in the study subjects

\begin{tabular}{|c|c|c|c|c|}
\hline & \multicolumn{2}{|c|}{ Females $(\mathrm{N}=24)$} & \multicolumn{2}{|c|}{ Males $(\mathrm{N}=27)$} \\
\hline & Before exercise/rest & Maximum/after exercise & Before exercise/rest & Maximum/after exercise \\
\hline \multicolumn{5}{|l|}{ Ventilation and lung volumes } \\
\hline Ventilation (I/min) & $\# 23.5 \pm 5.7 ; N=22$ & $83.5 \pm 12.3 ; N=23 *$ & $\# 24.9 \pm 5.1$ & $110.7 \pm 16.4 *+$ \\
\hline Normalized ventilation (I/min/kg) & $\# 0.39 \pm 0.08 ; N=22$ & $1.38 \pm 0.20 ; N=23 *$ & $\# 0.36 \pm 0.09$ & $1.61 \pm 0.26 * \dagger$ \\
\hline Ventilated lung volume (I) & $2.58 \pm 0.56$ & $3.55 \pm 0.54 ; N=19 *$ & $3.78 \pm 0.66+$ & $4.82 \pm 1.06 ; N=25 *+$ \\
\hline Normalized ventilated lung volume (1/kg) & $0.043 \pm 0.012$ & $0.060 \pm 0.012 ; \mathrm{N}=19 *$ & $0.055 \pm 0.011+$ & $0.071 \pm 0.016 ; \mathrm{N}=25$ *十 \\
\hline \multicolumn{5}{|l|}{ Metabolic factors } \\
\hline Blood lactate $(\mathrm{mmol} / \mathrm{l})$ & $1.60 \pm 0.31 ; N=22$ & $11.63 \pm 2.47 ; \mathrm{N}=23 *$ & $1.70 \pm 0.50$ & $13.03 \pm 3.22 * \dagger$ \\
\hline Blood pH & $7.356 \pm 0.030 ; \mathrm{N}=22$ & $7.254 \pm 0.049 ; \mathrm{N}=23 *$ & $7.354 \pm 0.027$ & $7.248 \pm 0.048 *$ \\
\hline Blood base-excess $(\mathrm{mmol} / \mathrm{l})$ & $0.76 \pm 1.07 ; \mathrm{N}=22$ & $-9.77 \pm 2.87 ; \mathrm{N}=23 *$ & $1.34 \pm 0.89$ & $-10.18 \pm 2.93 *$ \\
\hline Blood $\mathrm{HCO}_{3}^{-}(\mathrm{mmol} / \mathrm{l})$ & $24.4 \pm 1.0 ; \mathrm{N}=22$ & $16.6 \pm 2.0 ; \mathrm{N}=23 *$ & $24.9 \pm 0.8$ & $16.5 \pm 2.0 *$ \\
\hline
\end{tabular}

Values are expressed as mean \pm SD. Default number of subjects are $\mathrm{N}=24$ for female and $\mathrm{N}=27$ for male, respectively, otherwise the specific number of subjects included in the analysis is noted. \#) denotes that ventilation and lung volume measurements were performed with "Before exercise/rest" values recorded during the initial stable phase of exercise at 60 watt and compared to recordings made during maximum exercise. Metabolic factors were measured at rest before start of exercise and $10 \mathrm{~min}$ following the end of maximal exercise. $\left.{ }^{*}\right)$ denotes a statistical significant difference $(\mathrm{P}<0.05$, by ANOVA) comparing corresponding variable "Before exercise/rest" with "Maximum/after exercise". $\dagger$ ) denotes a statistical significant difference ( $<<0.05$, by ANOVA) comparing female and male subjects.

differences and/or similarities should be accounted for by sex when comparing boys and girls in this category of dynamically exercising [11] adolescents. A number of studies have evaluated $\mathrm{VO}_{2} \max$ in children and adolescents, and generally it appears that in children below 12 years of age $\mathrm{VO}_{2}$ max is slightly higher in boys than in girls, whereas differences begin to expand during adolescence $[5,7,8,12,13]$. Reaching adolescence, however, clinical and experimental data regarding ventilation, metabolism and hemodynamics are scarce and interpretation of test results and referencing is difficult.

In this investigation, we demonstrate lower resting and working blood pressures and higher resting heart rates in females, resting ECG patterns are similar except for QTc which is longer in females. Furthermore, aerobically trained adolescent girls and boys increase their heart rate and lactate levels to similar limits, being slightly higher in boys but without any detectable differences abroad the age-span investigated, in response to an aerobic maximal stress exercise test. Females and males exhibit similar maximum heart rates, which translate into a greater cardiac index in boys, being the one key factor leading to a greater peak $\mathrm{VO}_{2}$. The metabolic compensation, however, demonstrated a very similar adaption as $\mathrm{pH}, \mathrm{HCO}_{3}^{-}$, and the respiratory ratio (RQ) exhibit identical responses. Taken together, a pattern very similar to that observed in aerobically trained young adults $[8,9]$.

In terms of peak $\mathrm{VO}_{2}$, we observed absolute values similar to those previously reported in this age group [5]

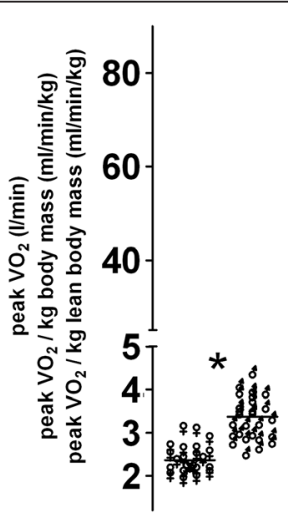

peak $\mathrm{VO}_{2}$

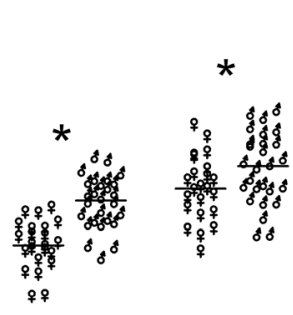

peak $\mathrm{VO}_{2} /$ peak $\mathrm{VO}_{2} /$ $\mathrm{kg}$ body mass $\mathrm{kg}$ lean body

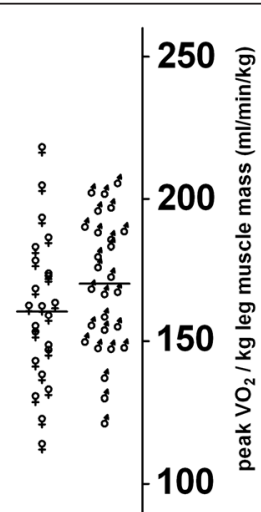

peak $\mathrm{VO}_{2} /$
kg leg muscle
mass

Figure 2 Oxygen uptake in boys and girls. Peak oxygen uptake (peak $\mathrm{VO}_{2}, 1 / \mathrm{min}$ ) and peak oxygen uptake normalized to total body mass $(\mathrm{ml} / \mathrm{min} / \mathrm{kg})$, normalized to estimated fat free mass ( $\mathrm{ml} / \mathrm{min} / \mathrm{kg}$ lean body weight), and normalized to estimated total leg muscle mass ( $\mathrm{ml} / \mathrm{min} / \mathrm{kg}$ leg muscle) in female $(+, \mathrm{N}=23)$ and male $(\hat{0}, \mathrm{~N}=27)$ subjects. $\left.{ }^{*}\right)$ denotes statistical significant difference $(\mathrm{p}<0.05$ by unpaired t-test with correction for multiple comparisons) between female and male subjects with regard to peak $\mathrm{VO}_{2}$, peak $\mathrm{VO}_{2}$ normalized to total body mass and estimated lean body mass, but not comparing peak $\mathrm{VO}_{2}$ normalized to estimated leg muscle mass. 
with a difference between females and males when comparing absolute peak $\mathrm{VO}_{2}$, peak $\mathrm{VO}_{2}$ normalized per kilogram total body mass, or lean body mass. When normalizing to estimated leg muscle mass, however, girls and boys demonstrated similar peak $\mathrm{VO}_{2}$. We take this to demonstrate that peak $\mathrm{VO}_{2}$ is balanced against leg muscle mass in aerobically trained adolescent girls and boys. This finding is in line with previous observations in adults [14-16] but not in children [7,13,17]. In the study by Sunnegårdh \& Bratteby [13], however, females exhibited lower levels of physical activity, as a contributory explanation for a lower $\mathrm{VO}_{2} \mathrm{max}$, and a possible sex difference in $\mathrm{VO}_{2}$ max normalized to estimated lean leg volume [15], in other words differences may be much smaller in trained compared to untrained subjects. When interpreting their data in relation to observations in children by Davies et al. [18] it appears that $\mathrm{VO}_{2} \max$ normalized to lean leg volume/leg muscle mass would be similar in boys and girls around 15-16 years of age [13] and older. Integrating these previous findings with observations from this investigation we propose that peak $\mathrm{VO}_{2}$ normalized to leg muscle mass is an acceptable clinical indicator to evaluate individual aerobic performance in relation to body composition and perform inter-sex comparisons in aerobically trained adolescents. In addition, the normalization of peak $\mathrm{VO}_{2}$ to estimated leg muscle mass, when compared to normalization to total body mass/lean body mass has an impact on the classification rank of training-level in girls, but much less so in boys.

Finally, when comparing the maximal exercise stress tests between girls and boys, we made the subjective observation that boys exhibit an operator-perceived degree of exercise stress that is more pronounced than in girls. Accordingly, the operator, without taking into account physiological measurements during the test would feel that the boys put in a greater effort than the girls, and that the girls appeared not to reach the point of total exertion. Examining the physiological responses of maximum heart rate or blood lactate levels, however, demonstrate that the girls are at a similar point of exertion as is the boys. We believe that this "wrong" perception that girls appear not to reach full exertion during testing is mainly caused by differences in ventilation volumes; with greater volumes and panting in boys (Table 2), leading to psychological perception of higher effort. Obviously, such a perceptive bias is important to note when working with exercise training in adolescent girls.

\section{Conclusions}

In conclusion, we demonstrate that the main factors to realize when working with aerobic training programs in female adolescents are: 1) resting blood pressure is lower, resting heart rate is higher and the ECG exhibits longer QTc interval when compared to males; 2) in response to a maximal bicycle exercise stress test maximum heart rate, maximum blood lactate levels and metabolic compensation are similar in adolescent females and males; 3 ) the increase in cardiac index during exercise is the key factor responsible for the greater absolute peak $\mathrm{VO}_{2}$ in adolescent boys compared to girls; 4) observed difference in peak $\mathrm{VO}_{2}$ per kilogram body mass comparing boys and girls disappears when peak $\mathrm{VO}_{2}$ is normalized to leg muscle mass only. This finding suggests that peak $\mathrm{VO}_{2}$ normalized to leg muscle mass could be a useful measure when comparing the degree of fitness between adolescent boys and girls in aerobic sports; and 5) there is a subjective operator-perceived impression that girls do not reach full exertion during testing, but physiological measurements clearly show a level of exertion similar to that of boys.

\section{Methods}

\section{Study subjects}

A total of 24 adolescent female and 27 adolescent male floor-ball players, i.e. an activity with a high dynamic (aerobic) component and a low/moderate static (anaerobic) component [11], were recruited from teams of a local floor ball club and investigated according to the protocol described below. All subjects and their parents gave written informed consent to participation following comprehensive oral and written information about the study protocol and the aims of the study. The investigation was approved by the ethical committee of Northern Stockholm (Young Athlete Heart Study, 2009/ 1246-31/1) and conformed to the principles set forth in the declaration of Helsinki.

\section{Study protocol}

The subject reported to the study room and underwent a health interview regarding family and personal medical history and a physical exam. The subject's height, weight and results of segmental body impedance were recorded. A standardized cardiac ultrasound examination was then performed.

Thereafter, a peripheral venous catheter was inserted into an ante-cubital vein and basal blood samples drawn. A baseline supine resting 12-lead ECG and blood pressure was recorded and the subject thereafter placed on the exercise bicycle instrumented with 12-lead exercise ECG electrodes, blood pressure measurement cuff, and a mouth-piece and nose-clip so that breath-by-breath ventilation, $\mathrm{O}_{2}$ and $\mathrm{CO}_{2}$ gas-exchange, and pulmonary blood flow by inert gas rebreathing technique could be measured.

The subjects then performed the exercise bicycle test using the same exercise protocol, starting at basal 60 watts load with 20 watts increments per minute, in both females and males. The subjects performed the test until 
self-experienced total exertion, and maximum stress of dyspnea, leg fatigue, and chest pain recorded by means of a modified visual-analog Borg scale ranging from 0 (no perceived stress) to 20 (maximum perceivable stress) $[19,20]$. Following the exercise test the subjects were deinstrumented and immediately placed in the supine position for recovery and post-stress blood samples were collected and the protocol terminated.

\section{Measurements}

\section{Total body impedance}

Subject body composition, i.e. body fat, water, and muscle composition, including segmental body and limb analysis of fat and muscle masses were measured by bioimpedance using a Tanita Body Composition Analyser BC 418MA device (Tanita, Helsinge, Denmark) [21]. Bioimpedance provides an acceptable estimate and was chosen over the more accurate dual energy $\mathrm{x}$-ray absorptiometry or magnetic resonance imaging because they were considered not to be ethically feasible in this investigation.

\section{Blood tests}

Before the exercise test baseline blood samples were collected for the analysis of blood chemistry including red blood cell count, hematocrit, total hemoglobin, mean corpuscular volume, mean corpuscular hemoglobin concentration, leukocyte count, platelet count, $\mathrm{Na}, \mathrm{K}$, creatinine, and forearm venous blood gas chemistry (ABL 700, Radiometer, Copenhagen, Denmark) for metabolic assessment (baseexcess, $\mathrm{HCO}_{3}^{-}, \mathrm{pH}$ ) and blood lactate concentration [22]. An additional forearm venous blood gas chemistry sample was drawn $10 \mathrm{~min}$ following maximal exercise stress for post-stress analysis.

\section{Echo-cardiography}

All subjects underwent a pre-study echo-cardiographic exam. A commercially available ultrasound apparatus (Vivid i, GE Vingmed, Horten, Norway) was employed for echo-cardiographic examinations using a standard phased 2.5 MHz multi-frequency transducer. The examinations were performed with the participant lying at the left lateral recumbent position at the end of expiration and the images acquired according to the recommendations of the European Society of Echocardiography from the parasternal and apical views [23].

\section{Blood pressure}

Resting blood pressure was recorded in the supine position using a semi-automatic blood pressure recording device (Omron 705IT, Omron Healthcare). During exercise systolic blood pressures were recorded using a blood pressure cuff and an ultrasound Doppler flow measurement probe positioned over the radial artery.

\section{Exercise stress bicycle setup and ECG-recording}

The stress test was performed on a Rodby Ergometer Bike RE990 stress test bicycle with a pre-loaded protocol (60 watt start / 20 watt increment/min) and an integrated standard 12-lead ECG recording (GE Case, GE Healthcare, Sweden). The 12-lead ECG was recorded at supine rest and during the whole exercise protocol to evaluate ST-segment deviations, arrhythmia and maximum heart rate.

\section{Ventilation, gas-exchange, pulmonary blood flow and cardiac output}

During the exercise stress test the subjects were connected to an Innocor $^{\circledR}$ device (Innovision, Odense, Denmark) through a breathing mouth piece with continuous inspiratory and expiratory gas sampling for analysis and flow measurement. Mouth-circuit breathing was secured by the subject wearing a tight nose-clip to prevent nasal ventilation. Ventilation, $\mathrm{O}_{2}$, and $\mathrm{CO}_{2}$ exchange was measured on a breath-by-breath basis and stored on the hard drive for subsequent analysis. Peak $\mathrm{VO}_{2}$ was derived as the average $\mathrm{VO}_{2}$ obtained during the final 30 seconds of exercise and normalized to total body weight, lean body weight, i.e. fat free mass, and estimated leg muscle mass respectively. Using the same Innocor ${ }^{\circledR}$ device, pulmonary blood flow was measured at baseline with the subject seated on the bicycle ergometer and at maximal exercise using the inert gas rebreathing technique. To measure pulmonary blood flow the subject performed 30 seconds of closed circuit rebreathing from a bag containing a gas mixture of $50 \% \mathrm{O}_{2}$, $5 \% \mathrm{~N}_{2} \mathrm{O}$ (soluble gas), $1 \% \mathrm{SF}_{6}$ (insoluble gas) in $\mathrm{N}_{2}$ diluted with ambient room air. The rebreathing bag volume was set individually in each subject as $30 \%$ above the expected tidal volume. Pulmonary blood flows and ventilated lung volumes were calculated using standard formulas as a part of the Innocor ${ }^{\circledR}$ software (Innovision, Odense, Denmark) $[24,25]$. Pulmonary blood flow was assumed to equal cardiac output as there was no pulmonary shunting of blood, and cardiac index was calculated from cardiac output according to standard formula.

\section{Statistical analysis}

Statistical analysis was performed using the Statistica v 10 (Statsoft Inc., Tulsa, USA). Unpaired t-test with correction (Newman-Keuls) for multiple comparisons was used to detect differences in selected variables between female and male subjects. Primary variables pre-defined for analysis were: Anthropometric data, peak $\mathrm{VO}_{2}$, peak $\mathrm{VO}_{2}$ per kilogram body mass, peak $\mathrm{VO}_{2}$ per kilogram lean body mass, peak $\mathrm{VO}_{2}$ per kilogram leg muscle mass, maximum heart rate and blood pressure during exercise, ventilation, ventilated lung volumes, ventilated lung volumes per kilogram body mass, changes in metabolic; i.e. base-excess and $\mathrm{pH}$ and lactate levels. ANOVA analysis with post-hoc 
testing corrected for multiple comparisons (NewmanKeuls) was used to analyze responses to exercise and effect of sex. $\mathrm{P}<0,05$ was considered statistical significant.

\section{Competing interests}

The authors declare that they have no competing interests.

\section{Authors' contributions}

ÅF: Conceived, planned and conducted the study, contributed to data analysis and intellectual contents of the manuscript. MA: Conceived, planned and conducted the study, contributed to data analysis and intellectual contents of the manuscript. HGS: Participated in the conduct of the study, and performed data analysis. Input on the intellectual contents of the manuscript. LHL: Contributed to planning of the study and contributed to intellectual contents of the manuscript. MS: Participated in the conduct of the study, and performed data analysis. Input on the intellectual contents of the manuscript. AM: Conceived, planned and conducted the study, performed data analysis and wrote the manuscript. AG: Conceived, planned and conducted the study, performed data analysis and wrote the manuscript. All authors read and approved the final manuscript.

\section{Authors' information}

Åsa Fomin and Mattias Ahlstrand were equal first author contributors. Aristomenis Manouras and Anders Gabrielsen were senior author contributors.

\section{Acknowledgements}

This study was supported by the Swedish Heart-Lung foundation. We thank Eva Wallgren, Department of Cardiology, Karolinska Institutet for important technical and analytical support.

Received: 27 February 2012 Accepted: 2 August 2012

Published: 20 August 2012

\section{References}

1. Armstrong $N$, McManus AM: Physiology of elite young male athletes. Med Sport Sci 2010, 56:1-22.

2. Stamatakis $\mathrm{E}$, Chaudhury M: Temporal trends in adults' sports participation patterns in England between 1997 and 2006: the Health Survey for England. Br J Sports Med 2008, 42(11):901-908.

3. Riksidrottsförbundet: Idrotten i siffror. Stockholm, Sweden: Riksidrottsförbundet; 2008 (www.rf.se).

4. Rowland T: Children's exercise phyiology, Chapter 5, 6. 2nd edition. Leeds, United Kingdom: Human Kinetics; 2005:89-133.

5. Rodrigues AN, Perez AJ, Carletti L, Bissoli NS, Abreu GR: Maximum oxygen uptake in adolescents as measured by cardiopulmonary exercise testing: a classification proposal. J Pediatr (Rio J) 2006, 82(6):426-430.

6. Rowland T, Goff D, Martel L, Ferrone L: Influence of cardiac functional capacity on gender differences in maximal oxygen uptake in children. Chest 2000, 117(3):629-635.

7. Rowland TW: Evolution of maximal oxygen uptake in children. Med Sport Sci 2007, 50:200-209.

8. Wilmore JH, Costill DL, Kenney WL: Physiology of sport and exercise, Chapter 18. 4th edition. Human Kinetics; 2008:422-446.

9. Drinkwater BL: Women and exercise: physiological aspects. Exerc Sport SCi Rev 1984, 12:21-51.

10. Astrand PO: Quantification of exercise capability and evaluation of physical capacity in man. Prog Cardiovasc Dis 1976, 19(1):51-67.

11. Mitchell JH, Haskell W, Snell P, Van Camp SP: Task Force 8: classification of sports. J Am Coll Cardiol 2005, 45(8):1364-1367.

12. Armstrong N, Williams J, Balding J, Gentle P, Kirby B: The peak oxygen uptake of British children with reference to age, sex and sexual maturity. Eur J Appl Physiol Occup Physiol 1991, 62(5):369-375.

13. Sunnegardh J, Bratteby LE: Maximal oxygen uptake, anthropometry and physical activity in a randomly selected sample of 8 and 13 year old children in Sweden. Eur J Appl Physiol Occup Physiol 1987, 56(3):266-272.

14. Cotes JE, Davies $C T$, Healy MJ: Factors relating to maximum oxygen uptake in young adult male and female subjects. J Physiol 1967, 189 (2):79P-80P
15. Davies $C T$ : The relationship of leg volume (muscle plus bone) to maximal aerobic power output on a bicycle ergometer: the effects of anaemia, malnutrition and physical activity. Ann Hum Biol 1974, 1(1):47-55.

16. Sanada K, Kuchiki T, Miyachi M, McGrath K, Higuchi M, Ebashi H: Effects of age on ventilatory threshold and peak oxygen uptake normalised for regional skeletal muscle mass in Japanese men and women aged 20-80 years. Eur J Appl Physiol 2007, 99(5):475-483.

17. Welsman JR, Armstrong N, Kirby BJ, Winsley RJ, Parsons G, Sharpe P: Exercise performance and magnetic resonance imaging-determined thigh muscle volume in children. Eur J Appl Physiol Occup Physiol 1997, 76 (1):92-97.

18. Davies $C T$, Barnes $C$, Godfrey S: Body composition and maximal exercise performance in children. Hum Biol 1972, 44(2):195-214.

19. Borg GA: Psychophysical bases of perceived exertion. Med Sci Sports Exerc 1982, 14(5):377-381.

20. Grant S, Aitchison T, Henderson E, Christie J, Zare S, McMurray J, Dargie H: A comparison of the reproducibility and the sensitivity to change of visual analogue scales, Borg scales, and Likert scales in normal subjects during submaximal exercise. Chest 1999, 116(5):1208-1217.

21. Pietrobelli A, Rubiano F, St-Onge MP, Heymsfield SB: New bioimpedance analysis system: improved phenotyping with whole-body analysis. Eur J Clin Nutr 2004, 58(11):1479-1484.

22. Williams JR, Armstrong N, Kirby BJ: The influence of the site of sampling and assay medium upon the measurement and interpretation of blood lactate responses to exercise. J Sports Sci 1992, 10(2):95-107.

23. Evangelista A, Flachskampf F, Lancellotti P, Badano L, Aguilar R, Monaghan M, Zamorano J, Nihoyannopoulos P: European Association of Echocardiography recommendations for standardization of performance, digital storage and reporting of echocardiographic studies. Eur J Echocardiogr 2008, 9(4):438-448.

24. Damgaard M, Norsk P: Effects of ventilation on cardiac output determined by inert gas rebreathing. Clin Physiol Funct Imaging 2005, 25 (3):142-147.

25. Gabrielsen A, Videbaek R, Schou M, Damgaard M, Kastrup J, Norsk P: Noninvasive measurement of cardiac output in heart failure patients using a new foreign gas rebreathing technique. Clin Sci (Lond) 2002, 102(2):247-252.

doi:10.1186/1471-2431-12-127

Cite this article as: Fomin et al:: Sex differences in response to maximal exercise stress test in trained adolescents. BMC Pediatrics 2012 12:127.

\section{Submit your next manuscript to BioMed Central and take full advantage of:}

- Convenient online submission

- Thorough peer review

- No space constraints or color figure charges

- Immediate publication on acceptance

- Inclusion in PubMed, CAS, Scopus and Google Scholar

- Research which is freely available for redistribution 